\title{
LA FENOMENOLOGÍA COMO VISIÓN PARA COMPRENDER EL ESPACIO ARQUITEGTÓNICO; UN VÍNCULO A TRAVÉS DE LA PERGEPGIÓN Y LA OBRA DE STEVEN HOLL
}

\section{PHENOMENOLOGY AS A VISION FOR UNDERSTANDING ARCHITEGTURAL SPACE; A LINK THROUGH THE PERGEPTION AND STEVEN HOLL'S WORK}

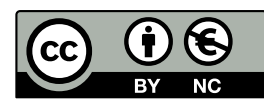

\author{
Juan Andrés Sánchez García \\ Universidad Veracruzana \\ México
}

Arquitecto de nacionalidad mexicana, graduado por la Universidad Veracruzana en 2012. Maestro en Procesos y Expresión Gráfica en la Proyectación Arquitectónica Urbana por parte de la Universidad de Guadalajara en 2015; Especialista en Métodos Estadísticos por parte de la Universidad Veracruzana en 2015, Candidato a Doctor en Arquitectura Diseño y Urbanismo por parte de la Universidad Autónoma del Estado de Morelos en 2019 y actualmente Doctorante en Arquitectura y Urbanismo por parte de la Universidad Veracruzana. Profesor de Tiempo Completo de la Universidad Veracruzana y su línea de investigación es la complejidad aplicada a la arquitectura y el urbanismo.

andressg89@hotmail.com / juansanchez@uv.mx

orcid.org/0000-0003-2217-2711

Fecha de recepción: 04 de abril, 2021. Aceptación: 30 de abril, 2021. 


\section{Resumen}

Este artículo tiene como objetivo mostrar la evolución del concepto de espacio arquitectónico y su importancia para leer la arquitectura, así como dotar al lector de una manera de entender al propio espacio a través de la fenomenología como un procedimiento que aboga por las emociones y percepciones, ya que permite al habitante experimentar el significado de la arquitectura.

La comprensión de la fenomenología en arquitectura es ayudado por la obra de Steven Holl, arquitecto norteamericano que presenta, a través de principios filosóficos, la manera de entrelazar los fenómenos en la arquitectura y que toma como ayuda al material para articular emociones en el habitante a través de un espacio emocionante que se percibe mediante los sentidos y lo vuelve el protagonista de propia arquitectura.

\section{Palabras clave}

Espacio arquitectónico, fenomenología, percepción, Steven Holl.

\section{Abstract}

This article aimed to show the evolution of the concept of architectural space and its importance for reading architecture, as well as to provide the reader with a way of understanding the space itself through phenomenology as a procedure that advocates emotions and perceptions within of space and that allows the inhabitant to experience the meaning of architecture.

The understanding of phenomenology in architecture is aided by the Steven Holl's work, an American architect who presents, through philosophical principles, the way of intertwining phenomena in architecture and who takes material as an aid to articulate emotions in the inhabitant through an exciting space that is perceived throu$\mathrm{gh}$ the senses and makes it the protagonist of architecture itself.

\section{Keywords}

Architectural space, phenomenology, perception, Steven Holl. 


\section{Espacio y Arquitectura}

Cuando se habla del término de arquitectura es casi imposible no tocar el término de espacio, que está inmerso en una cotidianeidad del ser humano; es decir todo lo que caminamos, miramos y donde nos encontramos pertenece al espacio.

Uno de los primeros acercamientos acerca del concepto de espacio, es el que describe cómo los primeros hombres que habitaron la tierra necesitaron contar con un lugar que les brindara seguridad y resguardo del medio ambiente (animales salvajes, clima extremo, etc.). Los nómadas encontraron refugio en cuevas; más adelante, cuando se volvieron sedentarios idearon la forma de construir viviendas en aquellos lugares que les proporcionaban mejores condiciones para la vida; esta manera rudimentaria de satisfacer sus necesidades de sobrevivencia, dio origen al espacio como principio de la arquitectura. El vínculo entre espacio y arquitectura ha llevado a estudiosos del tema a correlacionarlos como un binomio inseparable ya que incluso aparecen en algunas definiciones que se han dado acerca de la arquitectura en los últimos años.

Como menciona Kahn (1957), "la arquitectura es la creación meditada de espacios. (...) La renovación continua de la arquitectura proviene de los cambios en los conceptos de espacio", es la omnipresencia de la arquitectura ya que ésta se encarga de delimitar espacios y plantea cualidades que lo hace diferente y cuya materia prima serán los muros y las cubiertas, por lo que a nivel de composición también manifiesta articulación técnica y conceptual.

Los cambios en el concepto de espacio van marcando la pauta de la arquitectura y si se visualiza el espacio como un fenómeno que se puede analizar, entender, describir, articular y manipular, es posible utilizarlo como alma del proyecto arquitectónico, en otras palabras, como el "l'esprit nouveau" que plantea Le Corbusier o como el "spiritual refuge" que plantea Steven Holl.

Saber ver arquitectura es comprender el espacio, su significado, su contexto, su dinámica, su flujo y su expresión. "El espacio abstracto que defi- nimos sobre el plano se convierte en un lugar físico a través de la experimentación del espacio-tiempo" (Muñoz Cosme, 2008, p. 139). Esta experimentación es importante por ser el vínculo entre hombre y espacio, siendo esta relación el objetivo de la Arquitectura, como lo menciona Alberto Campo Baeza (2000) "creo con Heidegger que la Arquitectura trata de espacios para ser habitados por el hombre" (p. 38).

Si el espacio es la esencia de la arquitectura, esta se debe entender a través del vínculo con el hombre; bien establecido, algunos arquitectos como Steven Holl y Alberto Pérez Gómez se han basado en la filosofía para vincular el ser con el espacio y sensibilizar la experiencia para poder comprender que la arquitectura va más allá de un juicio estético o de apreciación, es decir a un plano oportunamente metafísico donde resalta la oportuna noción del ser.

Por ende, el hombre hace que el espacio cobre vida a través de la semiótica, significados, simbología, entre otros, que son expresados a través de fenómenos arquitectónicos y percibidos a través de la experiencia del hombre. Cada vez que se proyecta una obra arquitectónica se puede hacer uso de fenómenos que provoquen emociones adecuadas que posibiliten el bienestar al interior del espacio en correspondencia con uno de los propósitos de la arquitectura y acentuando las palabras de Plummer (2009) quien menciona que:

se desea de la arquitectura algo más que una mera satisfacción de básicas necesidades: se espera una satisfacción emocional, que los edificios cobren vida y que no se les considere objetos inertes; que afirmen los afectos creados como reflejo de los anhelos internos humanos; que propicien el contacto con el devenir de la naturaleza y abran la posibilidad de crear espacios que despierten nuevos sentimientos y sensaciones y, lo más importante, que satisfagan el espíritu propio (p. 6).

Las emociones que refiere Plummer (2009) son precisamente los estímulos, los impactos al ser, a la conciencia y al espíritu que hacen que el objetivo 
de la arquitectura sea aprendido al proceso de codificación para entender el concepto principal de la arquitectura expresada en una cualificación del espacio.

Para entender la evolución del concepto de espacio en arquitectura se empieza por visualizar el contexto en el que se fue dando. En la antigua Grecia, por ejemplo, tal como lo plantea Aparicio Guisado en su obra Construir con la razón y los sentidos (2008):

Los filósofos presocráticos se oponían a la noción de espacio y de materia, de tal manera que consideraban a ambos incompatibles, lo que derivó en el planteamiento de ciertas oposiciones análogas, como lleno-vacío, serno-ser, etc. (Aparicio Guisado, 2008, p. 53).

Estos argumentos, hasta cierto punto filosóficos, mantuvieron confusiones para poder definir al espacio, por lo tanto, no existía el concepto para los filósofos antiguos. Como refiere Aparicio (2008), en el libro el Timeo, Platón define al espacio como: "el habitáculo de las cosas creadas", y sostiene que el espacio en cuanto receptáculo es un continuo sin cualidades que no se halla ni en la tierra ni en el cielo, de modo que no puede decirse de él que existe.

En la antigüedad existió un debate filosófico acerca de lo que hoy llamamos espacio. Como lo refiere Ynzenga (2013) en su libro La materia del espacio arquitectónico: "no había concepto de espacio ni palabra para designarlo; y si no hay palabra no hay concepto ni pensamiento: lo que no es no puede ser pensado, y lo que no puede ser pensado no puede ser" (p. 25), por lo que en el pasado era difícil definir lo que no se conocía, por lo tanto no se le podía dar nombre a lo inexistente en nuestro imaginario ni a lo que se pretendía que no existiera.

Ambos arquitectos coinciden en la presentación del concepto de lugar antes de hablar del espacio y plantean la diferencia entre ambos. Mientras Aparicio Guisado (2008) recalca la necesidad de distinguir entre el espacio y el lugar basado en la dicotomía de espacio de necesidad (Utilitas) y un espacio de belleza (Venustas), Ynzenga (2013) plantea una definición concreta para separar ambos conceptos basada en que la cultura griega donde no hablaban de espacio, sino que:

Hablaban de tópos o lugar; un concepto íntima e indisolublemente vinculado a los objetos. Su noción de lugar no coincide con el contenido semántico -de sitio o emplazamiento- que hoy damos a esa palabra. Es decir, lugar representa la porción de nada, ocupada por un objeto; y su forma, la del volumen material que el objeto ocupa. Su lugar coincide con el límite matérico, lo que hoy entendemos como el 'volumen' que ocupa el objeto; como si ese volumen tuviese una realidad distinta o diferenciada de la del objeto en sí. Por tanto, para los filósofos griegos, si no hay cosa, no hay lugar, pues éste sólo existe como coincidencia con el límite de la forma. Ese era el lugar propio de cada objeto, el ídios tópos; tanto Platón como Aristóteles expresaron prácticamente esta misma comprensión del lugar. Al margen de objetos y sus tópos: nada; es decir, nada; ningún tipo de espacio (Ynzenga Acha, 2013, p. 26 ).

La relación existente entre el lugar y el volumen está basada en un concepto importante que lo define, la sombra. Así para Platón, el objeto revela el lugar, pero no lo crea. El objeto pertenece a lo real perceptible, pero el koinós tópos pertenece al mundo de las ideas, carece de realidad específica y sólo existe -como sombra- y cobra relevancia cuando se materializa en el límite de los objetos reales.

Para Aristóteles, en cambio, todo objeto ocupa algún lugar y si no hay objeto no hay lugar, pues sólo existe por razón del cuerpo que lo ocupa. Pero, "admite que el término lugar también puede utilizarse para referirse a lo que puedan tener en común los lugares específicos; lo que en términos más actuales se podría interpretar como posibilidad de que existan lugares" (Ynzenga Acha, 2013, p. 27).

Con base en lo anterior, se desprende que en la cultura griega era de interés la forma y la geometría de las cosas, sus relaciones y sus transfor- 
maciones. En su empeño por comprender el mundo material, los griegos se acercaron a la imitación de cánones, consolidando la relación entre las partes que componen un objeto para, posteriormente, entender lo que llamaríamos espacio, así como las cualidades que lo conforman.

Finalmente, Ynzenga (2013) concatena una forma de enlazar al lugar con el espacio a través de la escala, la luz, el cobijo, las distancias y las relaciones, en otras para determinar quizás, que hoy concebimos como espacio. Entonces, a partir del planteamiento anterior, se puede precisar que solo estando ahí, dentro del edificio, se logra percibir el espacio para aceptar su existencia a través de elementos que lo configuran. Pasó mucho tiempo para que la existencia de este término fuera aceptada, pues antes se construía sin saber que ahí mismo se encontraba el espacio o sin darle un nombre a lo que podíamos percibir.
Ynzenga (2013), más adelante en su investigación, propone que la aceptación de la existencia conceptual de un algo equivalente al espacio, 0 pheuma (equivalente a espíritu, soplo, hálito, viento), que describe metafóricamente una materia inmaterial, adquirió carta de naturaleza de la mano de la fe 0 , literalmente, de la teología. Finalmente, concluye:

Tras las adquisiciones neo-platónicas y aristotélicas, la convicción religiosa en la omnipresencia de Dios les llevó a negar la posibilidad de 'la nada'. Aceptar que allí donde no hay materia no existe nada, aceptar la no-existencia, implicaba la posibilidad de que hubiera un lugar inaccesible para el Creador o siendo que Dios es omnipresente no puede haber parte en la que Dios no pudiese manifestarse. En su lugar se vino a afirmar que el espacio 'es', que fue creado y que, como resultado de un acto de creación, fue perfecto desde sus inicios (p. 40).

Figura 1. Basílica de San Pedro. Arquitectura religiosa como precursora del espacio arquitectónico

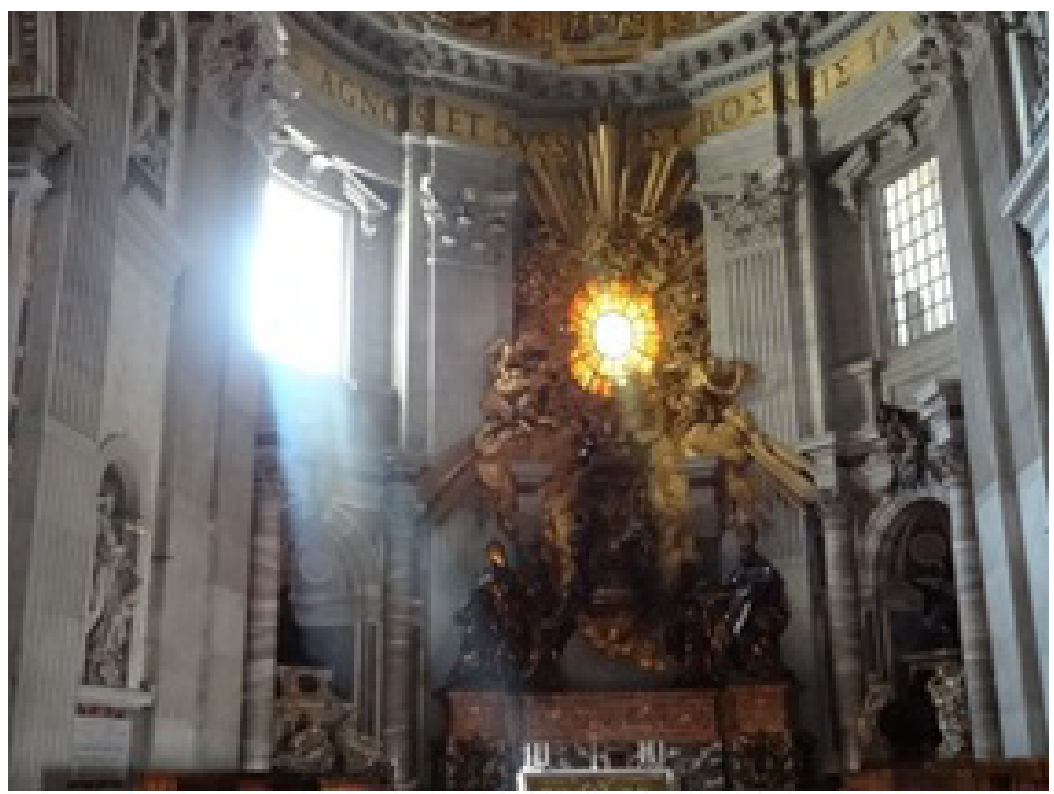

De Sánchez García, (2014).

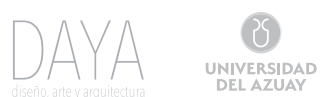


Como resultado, el espacio tuvo verbo y concepto. Adquirió un contenido continuo y difuso que resolvía, superándolo, el conflicto originario entre lo vacío y la nada, pero era incalificable. El espacio, por lo contrario, al existir como objeto real y conceptual, podía tener atributos, discernibles mediante la verdad revelada. Para la fe, para los tomistas (seguidores de Santo Tomas de Aquino), su principal atributo estaba en el hecho de que todas las cosas existentes comparten el haber surgido de un único acto de voluntad divina trascendente, y que, por tanto, reflejan con distintos grados de exactitud la perfección de su creador escondida en rasgos que la mirada atenta puede desvelar. Y fue en los templos, catedrales, donde la mirada fue más intensa, aupada en el impulso de la religión. "Aceptar la idea de que el espacio existe fue condición necesaria para comenzar a pensar en él y dotarlo de atributos. Inventado el sustantivo comenzaron a generar adjetivos" (Ynzenga Acha, 2013, pp. 43-44).

En el mundo occidental, a principios de la Edad Media, el concepto de espacio se distanció del concepto de la nada, superando la posible comprensión subjetiva que se podría obtener por el mero hecho de percibirla. Es decir, el edificio religioso cobró respeto y gran importancia para determinar la existencia del espacio como un elemento inteligible en la arquitectura que dotaba de simbolismo a la atmósfera presente. Desde el Renacimiento, y posteriormente el Barroco europeo, se concibe el espacio como una especie de "continente universal" de los cuerpos físicos.

Muchas interpretaciones de este concepto se han desglosado a lo largo de los años, y desde el siglo XIX se han originado distintas aproximaciones al problema del espacio desde múltiples disciplinas como la psicología, la geometría, la física e incluso desde la metafísica para entenderlo como una realidad.

De esta manera, en los años más recientes, se muestra que el espacio como tal, al ser sustantivo, puede adjetivarse cuando colocamos la palabra arquitectónico, es decir, dar referencia al espacio propio de la arquitectura.
Zevi (1981) plantea la importancia del estudio del espacio arquitectónico: "La arquitectura bella, será la arquitectura que tiene un espacio interno que nos atrae, nos eleva, nos subyuga espiritualmente (...). Pero lo importante es establecer que todo lo que no tiene espacio interno, no es arquitectura" (p. 26).

Cabe resaltar que "el espacio es un medio de expresión propio de la arquitectura y no es resultante de la orientación tridimensional de los planos y volúmenes" (Meissner citado por Muñoz Serra, 2012, p.1 ); por lo tanto, este espacio transmite a la arquitectura misma como si fuera su alma, es decir, tiene un contenido cargado de simbolismo e intencionalidad y lo importante es saber cómo definir o interpretar estas cualidades que ya posee el mismo espacio.

Cuando se admite la existencia de algo y se le da nombre de algo, comienza a ser. Adquiere nombre propio, pero aún no se sabe cómo es él. Tiene poca fisionomía. Gradualmente va cobrando rasgos propios. (...) el debate sobre ese algo deja de ser binario -existe 0 no existe- y pasa a ser cualitativo y estructural -cómo es y cuál es su lógica interna-. La capacidad de percibir dio paso a la capacidad de aceptar a entender, y está a la de proyectar (Ynzenga Acha, 2013, p. 43).

Dadas las nuevas tendencias de investigación, siempre será complicado visualizar y entender un concepto que es aparentemente pragmático; el mismo que es difícil medir con números fríos, es decir, tiene ciertas cualidades que no se pueden comprobar, pero que sí es posible demostrar a través de las nuevas líneas teóricas arquitectónicas que se han postulado en los últimos años.

Si se plantea la situación de espacio desde un punto de vista irracional, es más probable que se comprenda los factores que conllevan al espacio como el simbolismo, las sensaciones, las percepciones, la experiencia, entre otras, que ayudan a entender al espacio tal como es y tal como lo transmite la 
misma arquitectura. Para ello es necesario esquematizar sus características y especificar cómo podemos llegar a una realidad del mismo.

El concepto de espacio arquitectónico ha sido polémico, ya que se requiere comprender qué pasa dentro del edificio. La descripción de un espacio arquitectónico se torna problemática, pues para quienes la abordan es importante describir las cualidades y las características que ya posee, además de emitir ciertos juicios.

Con base en lo anterior, Casado Martinez, (2005) hace referencia al concepto de espacio como algo misterioso y que de cierta manera define la forma de percibir los lugares pero que conlleva un enigma importante en el concepto de límite para determinar la forma del mismo. En este sentido Alberto Campo Baeza (2010) define que: "El espacio conformado por la Forma, que traduce certeramente la idea, (...) es el resultado material, palpable, tangible de la Arquitectura" (p. 36).

Así mismo, José Ricardo Morales (2012) aborda al espacio arquitectónico como un elemento que contiene características y una función, es decir, transmite al espacio como una expresión de la cual se perciben ciertos elementos representativos cuando afirma que: "El espacio arquitectónico es fenoménico y pragmático, pues se manifiesta mediante operaciones humanas y tiene condición cualitativa. No se delata en el porcionamiento de cifra y medida: por el contrario, su carácter se evidencia en el tópos o lugar" (Morales, en Muñoz Serra, 2012, p. 2), y desde esta perspectiva, el espacio puede entenderse mediante tales relaciones humanas cualitativas que se presentan estando dentro del mismo espacio arquitectónico.

Pero, si la importancia del juicio arquitectónico radica en la comprensión del espacio interno, entonces se puede analizar la definición de Bruno Zevi (1981):

Es aquel espacio que, no puede ser representado completamente en ninguna forma, ni aprehendido ni vivido, sino por experiencia directa, es el protagonista del hecho arqui- tectónico. Tomar posesión del espacio, saberlo ver, constituye la llave del ingreso a la comprensión de los edificios (p. 20).

Del planteamiento anterior, se deduce que la experiencia permite, directamente, la relación del espacio interior con un edificio, así como en entenderlo de una manera sencilla y compleja, a la vez, por medio de la percepción.

Como resultado del intento de amalgamar el tema de la experiencia vivida con el proceso de conocimiento dentro de la arquitectura, el finlandés Juhani Pallasmaa, expresa en su libro Los ojos de la piel (1996) la importancia del sentido del tacto para la experiencia y la comprensión del mundo; asimismo, pretende crear un cortocircuito en el sentido de la vista y el del tacto; es más, asegura que a partir este último se puede distinguir una serie de colores, destacando la relación que tienen todos los sentidos como extensión del tacto para percibir el mundo exterior.

La arquitectura articula las experiencias del ser-en-el-mundo y lo fortalece nuestro sentido de realidad y del yo; no nos hace vivir en mundos de mera invención y fantasía (...) y en la experiencia del arte tiene lugar un peculiar intercambio; yo le presto mis emociones y él me presta su aura, que atrae y emancipa mis percepciones e ideas (Pallasma, 2006, p. 11).

Por tanto, su aportación radica en la importancia de la percepción de los sentidos para generar una experiencia arquitectónica que permite entender el mundo real. De la misma manera que Pallasmaa, Alberto Pérez Gómez introduce la aproximación a la espacialidad vivida y el pensamiento sensorial; con ello evoca pensamientos hacia una fenomenología existencial apuntalada por el trabajo del francés Maurice Merlau-Ponty, y expresa que en la arquitectura quien nos puede dar esa experiencia es la dimensionalidad; esta es variable por el tiempo y el espacio de cada individuo, no de una manera geométrica sino de una manera pre-conceptual de la percepción y de la conciencia del individuo, es decir, la experiencia va 
a depender del estado de ánimo, de lo ya vivido, de la memoria y del estado de conciencia.

Generar una experiencia dentro del espacio arquitectónico es necesario para entender lo que tal concepto nos puede transmitir, es una forma de entenderlo; por ello su importancia radica en saber apreciarlo y poderlo vivir percibiéndolo de una forma vivencial. La variedad de definiciones concernientes al espacio ha propiciado una serie de cuestionamientos sobre la forma en que dicho elemento se percibe como realidad tangible, la cual solo se puede entender a través de la percepción, incluso desde la infancia, el hombre desarrolla la capacidad de percibir mediante los sentidos. "El espacio es la materia de la arquitectura; constituye su interior, habitado y percibido, y refleja el condicionamiento de su exterior. Representa el ámbito por el que se desplazan el cuerpo y la mirada" (Ynzenga Acha, 2013 , p. 19). Por tanto, la manera en que se percibe el interior manifiesta la realidad de todo aquello que forma parte del espacio.

Si la experiencia es una forma de conocer el espacio como una realidad, la percepción es necesaria para generar conocimiento, como lo afirma Casado Martinez (2005):

Todo conocimiento se origina en la percepción mediante un completo proceso en el que intervienen cada uno los sentidos externos e internos. La percepción no involucra la retención de panorámicas, sino atisbos visuales de la realidad, los cuales se encuentran condicionados por límites espaciales observables. En este sentido, el observador es sujeto activo de la experiencia consciente del espacio percibido (p. 14).

Aunque el término percepción ha influido de forma relevante en la arquitectura, cabe destacar que dicho concepto proveniente de la psicología, la cual define percepción como:

la manera en que el individuo obtiene los conocimientos de su medio a fin de lograr una conducta adaptativa. (...) solo los estímulos que tienen valor de "señal", es decir, aquellos que desencadenan algún tipo de acción reactiva 0 adaptativa en el individuo, deberían denominarse información ( $H$. Forgus \& $E$. Melamed, 2010).

Por tanto, la percepción se describe como el proceso de extracción de información que tenemos del propio entorno en el que habitamos y además representa un tema vasto y complejo, incluso la estadística, como herramienta de investigación, se ha visto obstaculizada en su estudio, ya que han sido los experimentos los que han validado este elemento como foco de análisis. Sin embargo, cabe destacar que dicho término se ha utilizado de manera importante para lograr entender, valorar y cualificar el espacio arquitectónico, de tal manera que se ha concatenado con un término proveniente de la filosofía, es decir la fenomenología.

\section{La fenomenología de la arquitectura}

Desde Vitruvio, los arquitectos han tratado de entender cómo la arquitectura funciona como una forma de conocimiento. Este cuestionamiento se volvió más complejo en los inicios del siglo XIX, cuando la arquitectura deja de ser entendida como la representación de la imagen cósmica socialmente compartida. La cuestión de cómo el lenguaje poético y filosófico se refiere a la práctica arquitectónica se convierte en un campo de estudio.

En arquitectura, el fenómeno de la percepción ha llamado la atención de diferentes investigadores para debatirlo y analizarlo. Como ejemplo se hace referencia al noruego Cristian Norberg Schulz (2008), quien menciona:

La percepción nos proporciona el conocimiento inmediato del mundo fenoménico, es decir, el propósito de la percepción es suministrarnos una información que nos capacite para actuar de manera correcta, aunque ya sabemos que no es un elemento fidedig- 
no y que no nos transmite un mundo sencillo y objetivo (p. 20).

En este sentido se debe mencionar el hecho de que el mundo se compone de fenómenos tales como las experiencias. Retomando el trabajo "intenciones en arquitectura" de Cristian Norberg- Schulz (2008) [1965], refiere que la palabra fenómeno designa a todo aquello que puede experimentarse; en cambio, el término contrario nada no designa ninguna cosa, sino que expresa la ausencia de experimentación. Este hecho se vuelve trascendental debido a que todo objeto está representado por sus manifestaciones, sus fenómenos. Por ello también es posible denominar a estos "propiedades" porque no son una cosa, pero, como aclara Cristian, "pertenecen a la cosa de tal modo que la representan o simbolizan directamente y que, lo llamado "cosa" es no solo el conjunto de sus propiedades conocidas, sino el conjunto de sus propiedades aún no conocidas y conocidas.

Más allá de las formas, el espacio funge como un protagonista necesario en la experiencia arquitectónica. La relación consciente 0 inconsciente entre el espacio y las sensaciones o sentimientos de quien lo percibe, tiene dimensiones poéticas, fenomenológicas, simbólicas, atávicas y otras que abren fructíferas vetas de investigación y pensamiento. Es menester saber que las cualidades planteadas anteriormente manifiestan una posibilidad metodológica de profundizar más en cuestiones del espacio. Por ello, retomando a Ynzenga (2013), se debe recordar que antes de la percepción se encuentra el edificio, y que anterior a este, están el proyecto y el concepto. Se retoma el concepto del espacio como materia de arquitectura, como materia de proyecto y como entidad filosófico-conceptual. Este concepto se convierte en un factor de la articulación de los fenómenos complejos e intangibles percibidos en el espacio.

Para poder evidenciar la importancia en el desarrollo de metodologías cualitativas, Holl (2011) plantea que "el desafío de la arquitectura es estimular tanto la percepción interior como la exterior; realzar la experiencia fenoménica mientras, simultáneamente, se expresa el significado, y desarrollar esta dualidad en respuesta a las particularidades del lugar y de la circunstancia" (p. 12). Lo anterior muestra la relevancia que tiene la interpretación de las relaciones entre ser humano y el espacio arquitectónico para poder comprenderlo.

La fenomenología, como un método de análisis de conocimiento, ha manifestado una evolución que, desde el principio del siglo XX, ha pretendido aportar una forma de ver las ciencias sociales $y$ empíricas.

La fenomenología, entendida como "un estilo radical de filosofar que enfatiza el intento de llegar a la verdad de las cuestiones, de describir los fenómenos, en el más amplio sentido, de todo lo que acontece ante los ojos del observador" (Moran, 2011, p. 4), es una corriente filosófica originada por Edmund Husserl a mediados de 1890. Cabe destacar que, en su concepción pura, Alvarez-Gayou (2013) destaca que la fenomenología descansa en cuatro conceptos clave: "la temporalidad (el tiempo vivido), la espacialidad (el espacio vivido), la corporalidad (el cuerpo vivido) y la relacionalidad y comunalidad (la relación humana)" (p. 85).

Si bien se considera a Edmund Husserl como padre de esta metodología desde sus publicaciones como La crisis de las ciencias europeas y la fenomenología trascendental (1936), autores como Alfred Schütz y Thomas Luckmann han retomado lo escrito por Husserl y plantear aportaciones válidas para el desarrollo de la investigación cualitativa.

Alfred Schütz describe a la fenomenología como una filosofía del ser humano en su mundo vital,

capaz de explicar el sentido de este mundo vital de una manera rigurosamente científica. Su objeto es la demostración y la explicación de las actividades de conciencia de la subjetividad trascendental dentro de la cual se constituye el mundo de la vida (Dreher, 2015, p. 73).

Si bien Schütz retoma las ideas de Max Weber, también se valió de la filosofía de Henri Bergson quien planteaba la conciencia subjetiva en un análisis de tiempo o duración que complemen- 
ta al concepto de espacio en la experiencia interna del hombre. En este marco de tiempo que propone Schütz, plantea una diferencia al individualismo de Weber ya que, al no tener en cuenta la temporalidad, se pueden emitir juicios erróneos o malentendidos con respecto a la interpretación de la realidad que presuponemos construimos con nuestras mentes para intentar vivir el espacio.

Es necesario hacer referencia que Schütz destaca las tres dimensiones del mundo de la vida: una estructura espacial, una temporal y una social del mundo de vida. Con ello marca una forma de relacionar al espacio-tiempo con el aquí y ahora para vivirlo y lo complementa con esta estructura social de vivirlo cara a cara, siendo única nuestra experiencia vivida dentro de un espacio y lo constituye nuestra percepción del mundo real. Esto es lo que nos hace diferente al mundo de las máquinas, lo que nos hace únicos y lo que nos hace generar emociones en un mundo fascinante dentro del espacio.

Estas percepciones hacen que dentro del espacio no haya una realidad 0 una verdad en concreto, sino que abre el panorama a la admisión de la subjetividad. Luckmann, por otra parte, toma los principios del método de Husserl como un método para explorar el ser subjetivo y la vida subjetiva de universales y plantea lo que llama "ego fenomenológico" y cuya aportación es describir la experiencia de una forma metodológicamente rigurosa y controlada, es decir realizar esta descripción crítica sin llegar a tener que emitir algún juicio.

Es interesante poner en perspectiva autores como Zygmunt Bauman (1976) que critica el hecho de que la sociedad ingresa en el mundo del individuo como mitos a través de la abstracción y se quedan solo en conceptos mentales en contraposición de lo que menciona Schütz. Jürgen Habermas y Pierre Bourdieu también han criticado los "subjetivismos" planteados en esta metodología y este último es quien introduce el término de "habitus" como un sistema de modelos de percepción y comprensión para intentar reducir la separación de lo subjetivo y lo objetivo; entonces si podemos auxiliarnos de que, bajo la fenomenología, la construcción de una realidad proviene de la manera en que percibimos y la manera en que lo comprendemos.

Si se parte de una cuestión filosófica, la falta de una definición común de fenomenología se confirma por muchos fenomenólogos Merleau-Ponty (1962), Mooney (2002); Moran, (2005) etc. Reza Shirazi (2014) en su obra Towards an Articulated Phenomenological Interpretation of Architecture: Phenomenal Phenomenology describe las interpretaciones de fenomenología para algunos autores, mientras que para Husserl era "un retorno a las cosas mismas", para Heidegger era "una forma de ver" y para Merleau -Ponty "la esencia de la percepción".

Reza Shirazi (2014), retoma a Morán (2000) para sugerir que la fenomenología es más "una práctica en lugar de un sistema", y que probablemente debido a este carácter práctico, la fenomenología es de interés para los arquitectos que detectan un potencial concreto en sus concepciones y en los temas más filosóficos.

Pau Pedragosa (2014), de la Universidad Politécnica de Cataluña, dispone de una confianza hacia este método, basado en la obra de Robert Sokolowski, porque es una visión que hace crítica de la ciencia natural, pues se cree que la visión racional ha acaparado muchos frentes en la investigación, y que la fenomenología es una ciencia humana, académicamente hablando. Además, menciona que esta visión evalúa las cualidades, empezando por las emociones, los valores estéticos, el arte, la política, la conducta, etc., de una manera introspectiva, es decir, hacia adentro. De esta forma, la fenomenología significa comenzar a hacer filosofía (en este caso de la arquitectura) o los principios de una teoría ya que, como asegura Kahn, corresponde al comienzo del andar, cuyo fin siempre tendrá una intencionalidad, ya que lo que percibe es lo que se piensa, lo que se ve y se siente. En otras palabras, no es decir qué es, sino cómo se observa, incluyendo esta parte simbólica, mística y hasta poética del mismo espacio (Pedragosa Bofarull, 2014). Estos enfoques fenomenológicos se han empleado tanto en la teoría como en la práctica arquitectónica. 
Esta forma de filosofía o metodología social ha motivado a arquitectos a recurrir a conocimientos básicos para decodificar las esencias de la arquitectura y poder generar nuevas teorías. Es importante destacar como una línea teórica e importante lo que se ha establecido a través de la arquitectura. Desde el lado conceptual y retomando Reza Shirazi (2014), críticos afirman que la fenomenología puede proporcionar una manera verdadera y confiable de comprender la arquitectura. Ellos argumentan que la fenomenología puede localizar la esencia de las cosas y de los fenómenos de tal modo que permitan la experimentación existencial. Estos estudiosos no solo tienen enfoques fenomenológicos desarrollados para entender la arquitectura, sino que consciente 0 inconscientemente han tratado de evaluar las obras de arquitectura, estilos y movimientos bajo distintos criterios fenomenológicos.

Norberg-Schulz hace hincapié en que la fenomenología es "un método muy adecuado para penetrar en el mundo de la existencia cotidiana" (Norberg -Schulz 2000, p. 15). Este autor fijó sus trabajos en la investigación de Martin Heidegger, quien considera a la fenomenología como un método con el cual se puede entender el mundo, incluyendo el mundo de la arquitectura. Partiendo de los conceptos formulados por Bacherlard, Heidegger y Merleau-Ponty, Norberg trata de atraer la atención hacia las realidades cualitativas y poéticas de la arquitectura, cuya tarea principal es crear el "alma del lugar".

En un sentido filosófico más amplio, el teórico Alberto Pérez-Gómez sostiene que en una época en que la arquitectura ha perdido su dimensión metafísica y ya no es una forma privilegiada de la reconciliación la gente del mundo, sólo la fenomenología puede redescubrir la primacía de la percepción y superar el dilema fundamental que la filosofía moderna heredó de Descartes. Al revelar las limitaciones de la razón matemática, la fenomenología ha indicado que la teoría tecnológica por sí sola no puede ponerse de acuerdo con los problemas fundamentales de la arquitectura. En cambio, "la arquitectura contemporánea, desilusionada con las utopías racionales, se esfuerza en romper las obse- siones positivistas de encontrar una nueva justificación metafísica en el mundo humano, y su punto de partida es una vez más la esfera de la percepción, el origen último de sentido existencial" (Pérez-Gómez 1983, p. 325).

Los aportes de dichos teóricos y la comprensión del valor de la fenomenología aplicada a la arquitectura de los edificios para facilitar las ideas de diseño, valoran a la fenomenología como una "manera", "método" o "enfoque por el cual los problemas arquitectónicos pueden ser mejor identificados y aclarados. La sugerencia es que la fenomenología ofrece una vía hacia una comprensión más profunda, más amplia de temas y problemas arquitectónicos (Reza Shirazi, 2014).

Se debe hacer hincapié en que la fenomenología ha sido un elemento importante en la práctica de los arquitectos involucrados en el diseño del mundo real, pues el estudio fenomenológico de temas arquitectónicos les permite pensar profundamente sobre estos temas y evocar imágenes y detalles más útiles.

La fenomenología es una manera peculiar de ver, de pensar, de diseñar y de comprender al espacio arquitectónico. Aunque la fenomenología recurre a la experiencia vivida como auténtica filosofía, también se basa en la percepción de las condiciones pre-existentes. Hacer una arquitectura no empírica exige la concepción de una idea formativa, en la que cada proyecto debe contar con la información y el desorden, así como con la confusión de propósitos, la ambigüedad del programa y una infinidad de materiales y formas (Artemis, 1993, p. 21) para poder entender su verdadera esencia.

\section{La fenomenología de Steven Holl}

El norteamericano Steven Holl, uno de los principales exponentes de la fenomenología arquitectónica, escribe Cuestiones de percepción; 
una fenomenología de la arquitectura con miras al debate de la introducción de nuevos instrumentos para el estudio de la arquitectura, e intenta explicar el papel que desempeñan la percepción humana, la experiencia fenoménica y la intuición en la experiencia y la formación perceptiva del espacio construido; entre otras cuestiones, manifiesta que las zonas fenoménicas son causas de los elementos fenomenológicos que permiten la percepción, tales como el agua, el sonido, el agua, la luz y la sombra, elementos que forman parte de los configuradores y calificadores del espacio arquitectónico.
La búsqueda e interpretación de las experiencias que generan una percepción dentro del espacio arquitectónico ha sido tema distintivo en la obra de Holl al subrayar que "el desafío de la arquitectura consiste en estimular la percepción interior y la exterior, en realzar la experiencia fenoménica mientras, simultáneamente, se expresa el significado, y desarrollar esta dualidad en respuesta a las particularidades del lugar y de la circunstancia" (Holl, 2011, p. 12), premisa que manifiesta una tendencia importante para hacer que lo que pase dentro del espacio arquitectónico sea estimulante.

Figura 2. Concept diagram for D. E. Shaw Offices, New York, 1992 Existing windows with new back-paint bafles

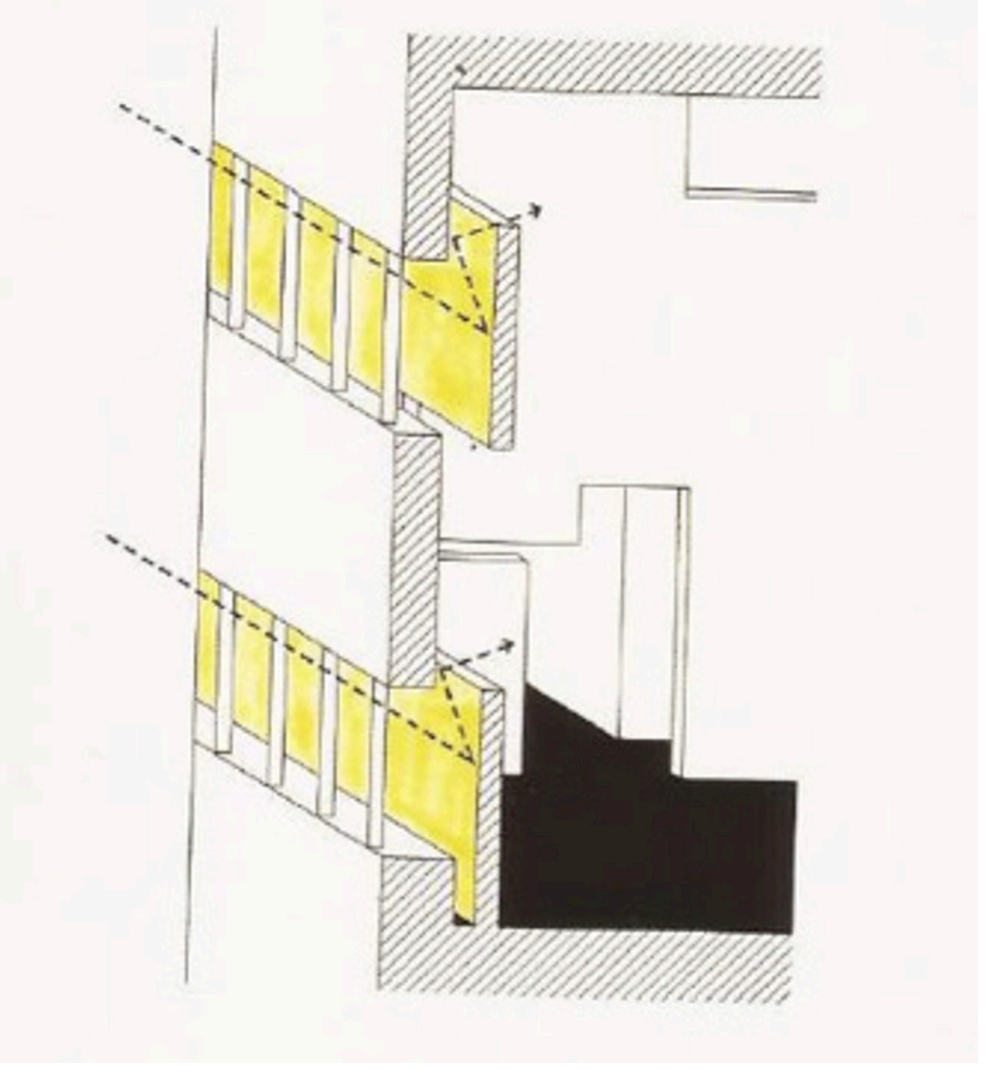

De Parallax, (2000, p. 164).

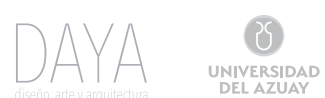


Figura 3. View from second level with reflect color

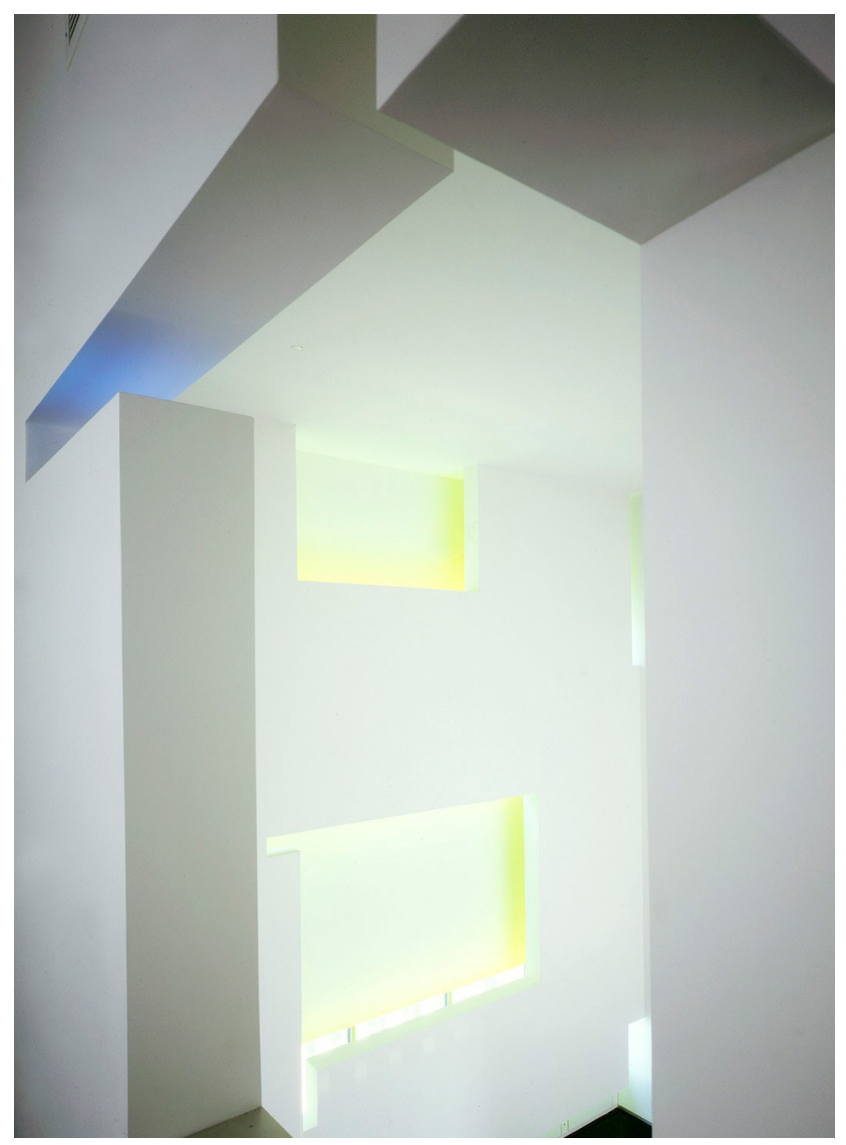

De Parallax, (2000, p. 164).

Steven Holl (1996) retoma los fundamentos Maurice Merleau-Ponty, quien dedicó parte de su vida al estudio de la percepción a través del lenguaje técnico de la fenomenología y que, en su libro de Lo visible y lo invisible (1966), propuso un desafío singular a los arquitectos. Merleau Ponty en su trabajo demostró que la percepción y la comprensión de la humanidad son eventos más misteriosos de lo que los modelos científicos deterministas nunca han sido capaces de captar y que su objetivo es precisamente la noción de la experiencia. Esto sugiere la posibilidad de una arquitectura que puede ser capaz tanto de manifestarse y constituirse en sí a través de experiencia, como una noción no idealizada.
Entre las afirmaciones de Holl, es importante destacar:

La fenomenología se refiere al estudio de las esencias, y la arquitectura tiene el potencial de poner esencias de nuevo en existencia. Por la forma, el espacio y la luz de tejer, la arquitectura puede elevar la experiencia de la vida diaria a través de los diversos fenómenos que surgen de sitios específicos, programas y arquitecturas. Por un lado, una arquitectura de idea -fuerza; en otro, la estructura, el espacio material, el color, la luz y la sombra se entrelazan en la fabricación 
de la arquitectura (Holl 1996 citado por Reza Shirazi, 2014, p. 99).

Los fenómenos a los que hace referencia Holl, son los encargados de concatenar la experiencia dentro del espacio, incluso crear la arquitectura misma. En la práctica arquitectónica que realiza Steven Holl diseña los imaginarios mediante la re- presentación en acuarelas, actividad que propicia la concepción gráfica de cómo espera que se comporte el espacio a través de configuradores como la escala, la forma 0 la propia luz. Esta manera de idear el espacio la lleva a cabo en sus diseños como en la propuesta que realizó para el proyecto de "The Pinault Foundation" en París, Francia en 2001.

Figura 4 (a). Boceto de "The Pinault Foundatio". Le Seguin, Paris, France 2001

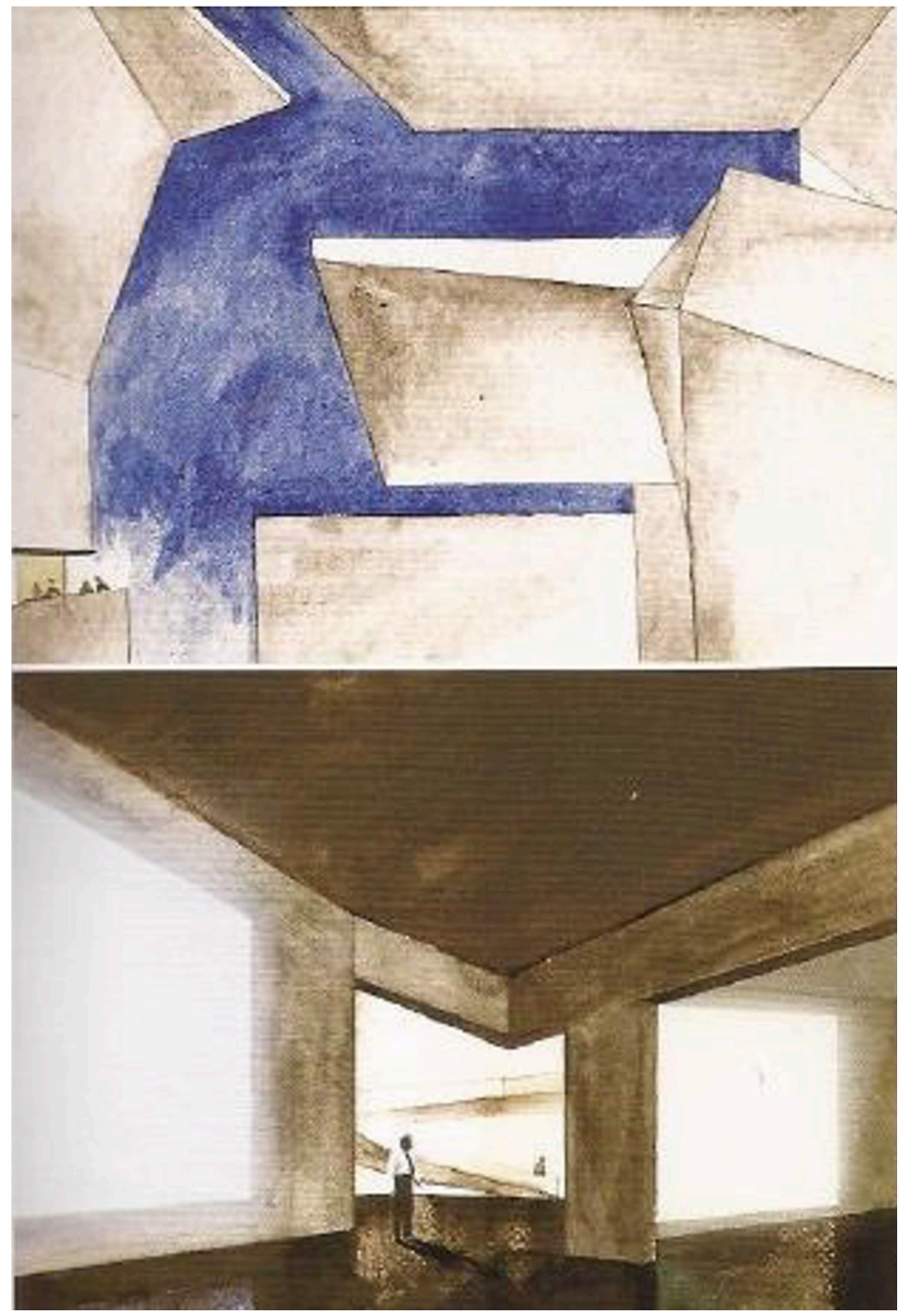

De Luminosity/Porosity, (2006, p. 86).

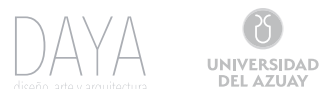


Figura 5. "The Pinault Foundatio". Le Seguin, Paris, France 2001

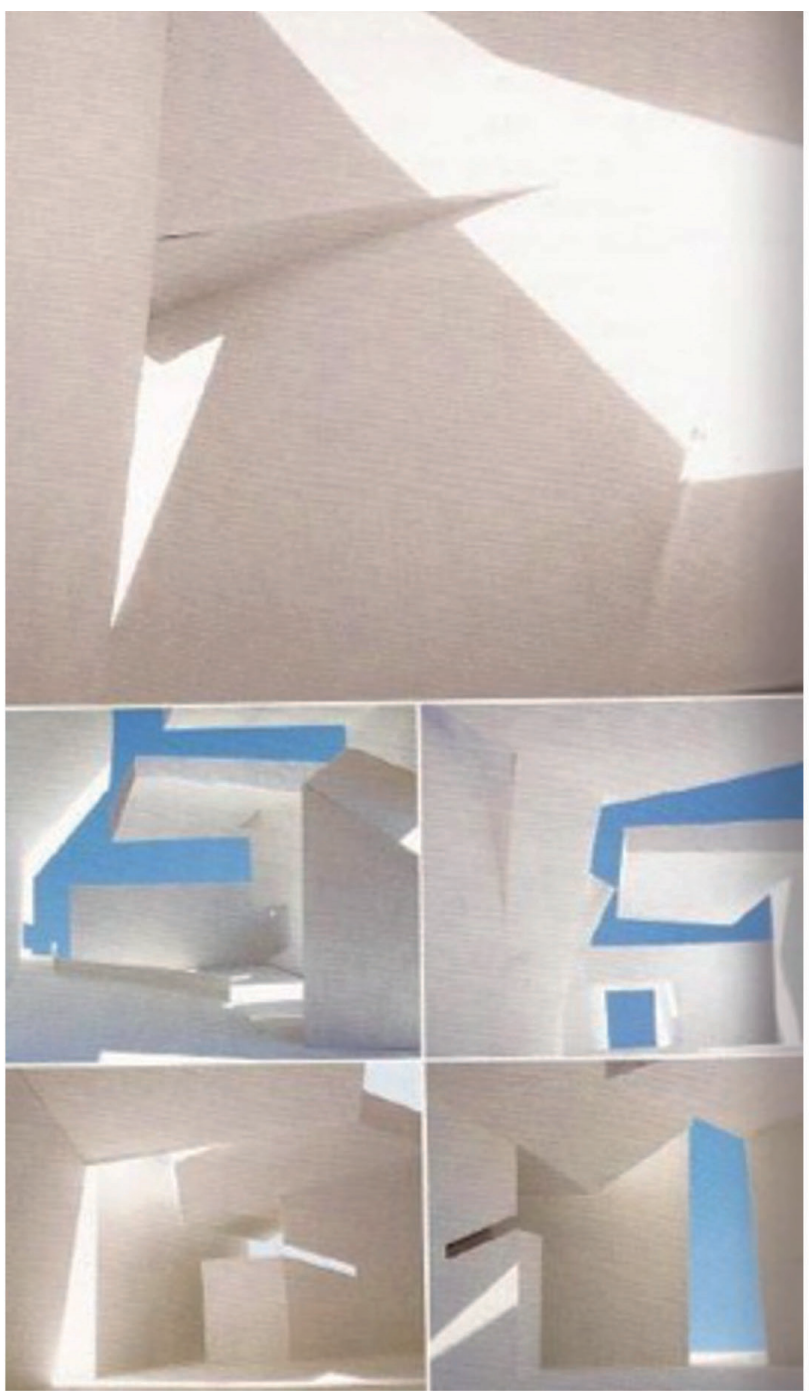

De Luminosity/Porosity, (2006, p. 86).

Cabe hacer una mención especial de la teoría y obra de Steven Holl, en razón de que, conjuntamente con el análisis fenomenológico del espacio, introduce un término denominado intertwining, en español entrelazamiento, a la arquitectura contemporánea de finales del siglo XX, cuando menciona lo siguiente:
The early modern architects rationalize the use of light in buildings and called for the hygienic benefits of plate glass. Today we also understand the importance of the subtleties and psychological differences of a vast range of qualities of light. With as much attention to darkness and to the contrasting secrets of light 
and dark, we engage in metaphysics of lights. Night's darkness evokes a connection to Dionysian archetypes and mysteries, while the bright light of day is Apollonian, exuberant and unconcealed. Metaphysics of light is part of intertwining essences with everyday materials, forms and spaces (Frampton, 2003, p. 16).

Figura 6. "Words are his sails... the way they are set turns them into concepts" Walter Benjamin

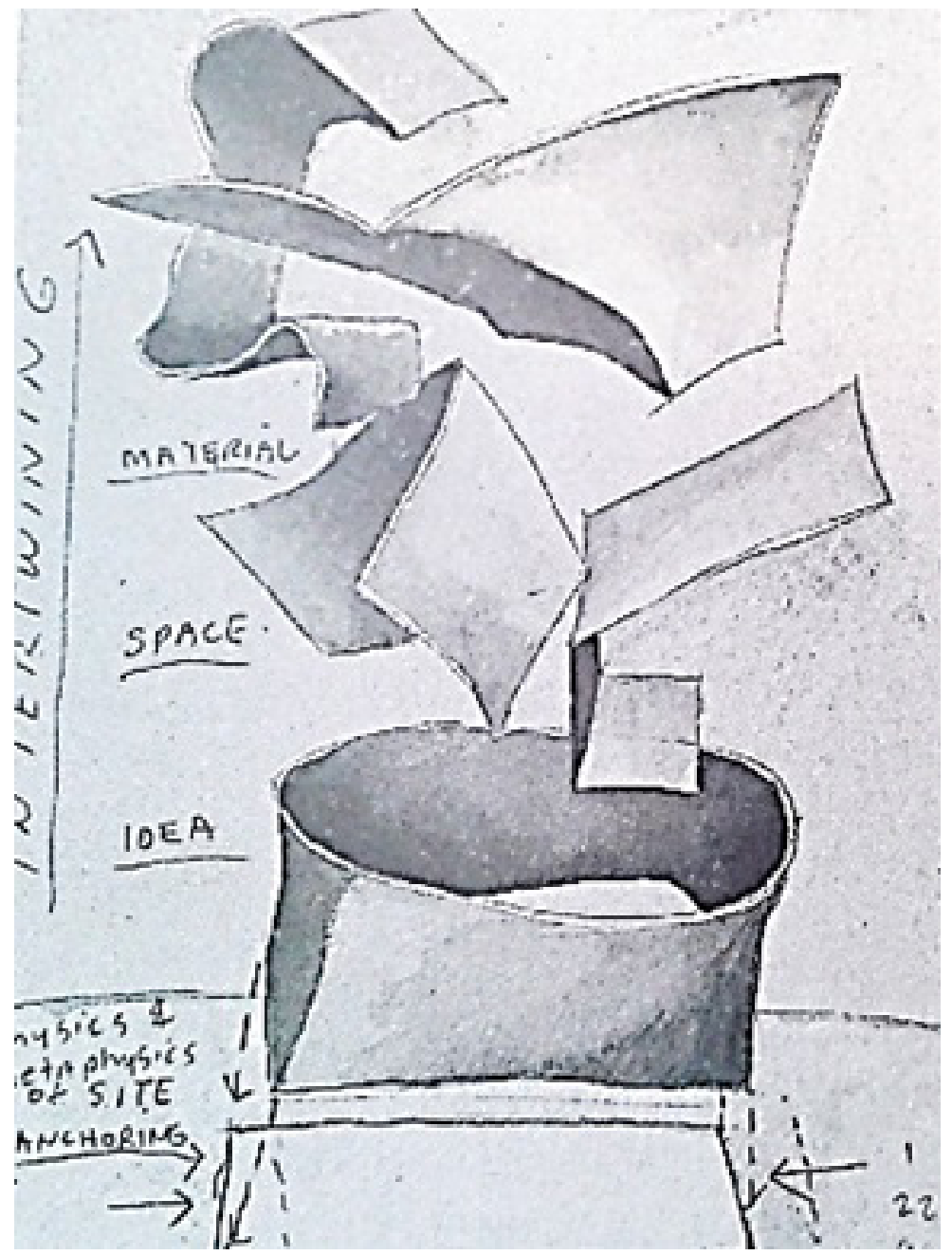

De Intertwining, (1996, p.14). 
El autor plantea la relevancia del juego entre la luz y la sombra como parte de los matices psicológicos que se manifiestan cuando se diseña y se construye a través de estos elementos. Con esto conforma una metáfora filosófica, pragmática y poética para poder evocar los arquetipos; en otros términos, el carácter y la espiritualidad de la arquitectura.

Mientras que la fenomenología se refiere al estudio de las esencias, la arquitectura tiene el potencial de poner dichas esencias en existencia, ya que tiene la capacidad de dar forma a un vívido y percibido entrelazamiento del espacio y el tiempo. "Reuniendo forma, espacio y sombra, la arquitectura puede elevar la experiencia de la vida cotidiana de las personas a través de la percepción de varios fenómenos que surgen de sitios y arquitecturas específicas" (Holl, 1996, p. 11).

Holl muestra también un intento por ligar sus teorías y pensamientos con la construcción de edificios tangibles con las mismas propiedades fenomenológicas, con el siguiente objetivo: "Our aim is to realize space with strong phenomenal properties while elevating architecture to a level of thought" (Nuestro objetivo es hacer realidad el espacio con fuertes propiedades fenomenales mientras se eleva la arquitectura a un nivel de pensamiento) (Holl, 1996 en Garofalo, 2003, pp. 9-10). Por lo anterior, se considera fundamental convertir esas percepciones en emociones fenomenales.

Figura 7. Cranbrook Institute of Science, Michigan 1999

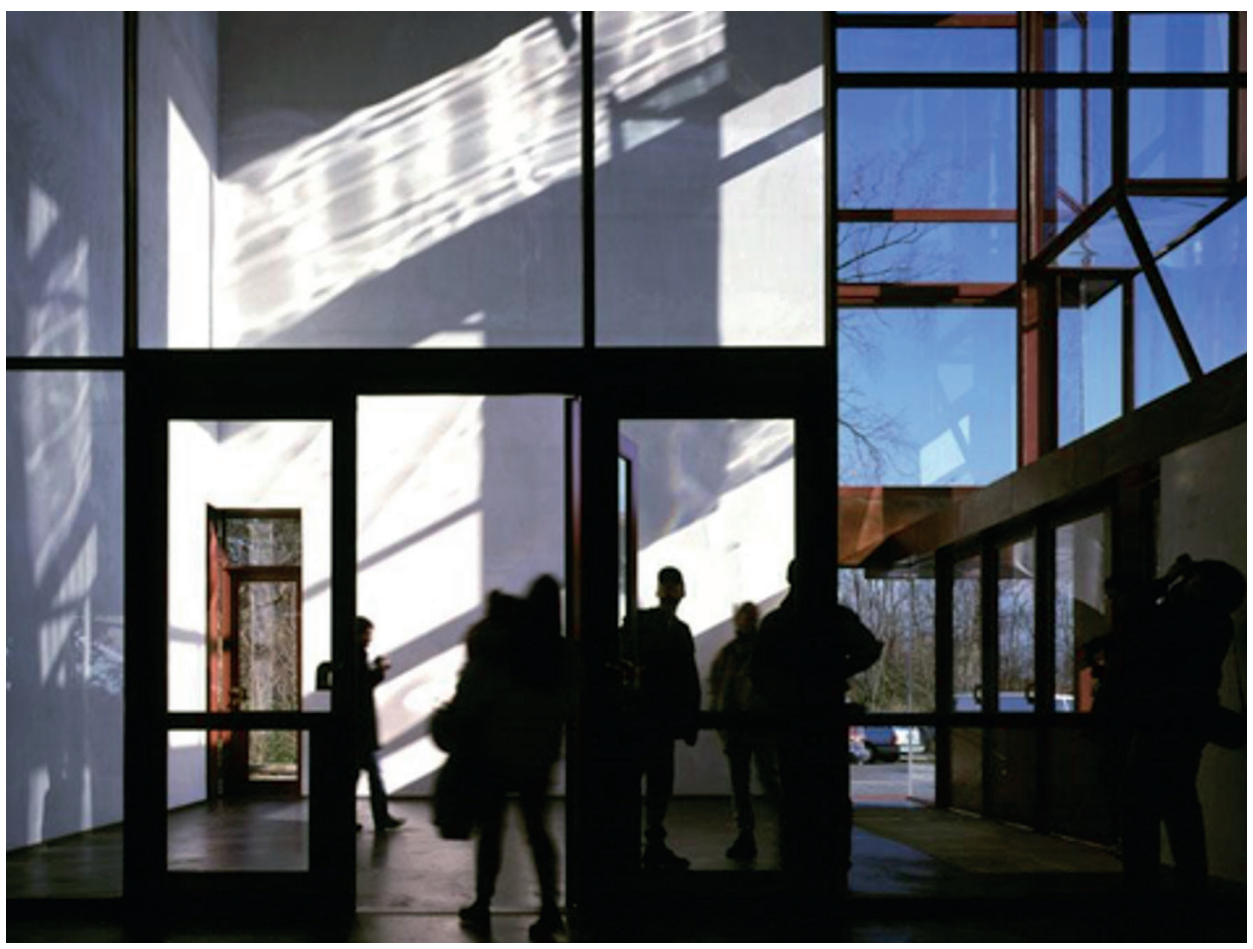

De Holl, S., (2015, www.stevenholl.com). 
Una obra importante en la que Holl plasma su teoría es la del Crabrook Institute of Science, Bloomfield Hills, Michigan, terminada en 1999. El autor no se limita a su afición por las combinaciones fenomenológicas, sino que se expresa invariables en la construcción en sí, para dar una tectónica que, sin embargo, silenciado, surge de la tecnología empleada y el carácter táctil de los materiales.

Hoy en día la arquitectura tiene cualidades artísticas y humanísticas. Este humanismo fusiona vidas subjetivas y objetivas, entrelazando sentimientos internos y externos, el pensamiento interior y exterior, en un fenómeno. "La experiencia de los materiales en la arquitectura no es solo visual sino táctil, auditiva y olfativa; estas formas de percepción, unidas al espacio y a la trayectoria corporal en el tiempo, permiten llegar a la experimentación sensorial" (Holl, 1996, p. 16).

Así, su obra y teoría logran dos cosas muy importantes: la primera es crear una filosofía de la arquitectura, es decir, transformar la percepción del objeto y del espacio. La segunda es que posibilitan manejar los volúmenes, colores, formas, luces, texturas, circulaciones, movimiento y velocidad junto con el espacio; asimismo, sugiere la utilización de estas herramientas para la generación de una poética y una espiritualidad de la arquitectura, expresión similar a la de Norberg Schulz cuando refiere al alma del lugar.
Para sintetizar la visión que Holl plantea en sus proyectos es necesario concluir con el abordaje de los puntos que este autor considera más relevantes. El primero es el alma, la cual se encuentra en "la atención al detalle que se destila en el espacio concretado en el amor de la construcción" (Artemis, 1993, p. 25). Estos detalles se pueden lograr con los efectos intangibles que producen algunos materiales. Como segundo punto, Holl se refiere a la idea, enlazando siempre los opuestos de la racionalidad y el sentimiento.

En cuanto al campo intelectual, las ideas están en equilibrio con lo real de la experiencia, de los fenómenos y de la forma en que se da significado. Debido a este equilibrio, la arquitectura tiene tanto la intensidad intelectual y la física que potencializan la mente, los ojos y el alma (Artemis, 1993).

La concepción del alma y la idea manifiestan la posibilidad de crear fenómenos que otorgan un significado particular al espacio arquitectónico y a la arquitectura misma, reflejados en edificios que pueden ser percibidos y entendidos cuando la experiencia genera un mundo de conocimientos.

Otro ejemplo del cual partirá el análisis sintético es Stretto House, construcción elaborada por Holl en 1991, en la cual aplica dos conceptos y básicos: si se coloca un concepto de material que evoque el sonido, se obtiene el tiempo, y si se coloca el material que nos evoque la luz, se obtiene el espacio. Así, Holl manifiesta la importancia de aplicar los conceptos fenomenológicos para crear estas atmósferas y provocar sensaciones que se traducen en un lenguaje arquitectónico. 
Figura 8. Stretto House de Steven Holl

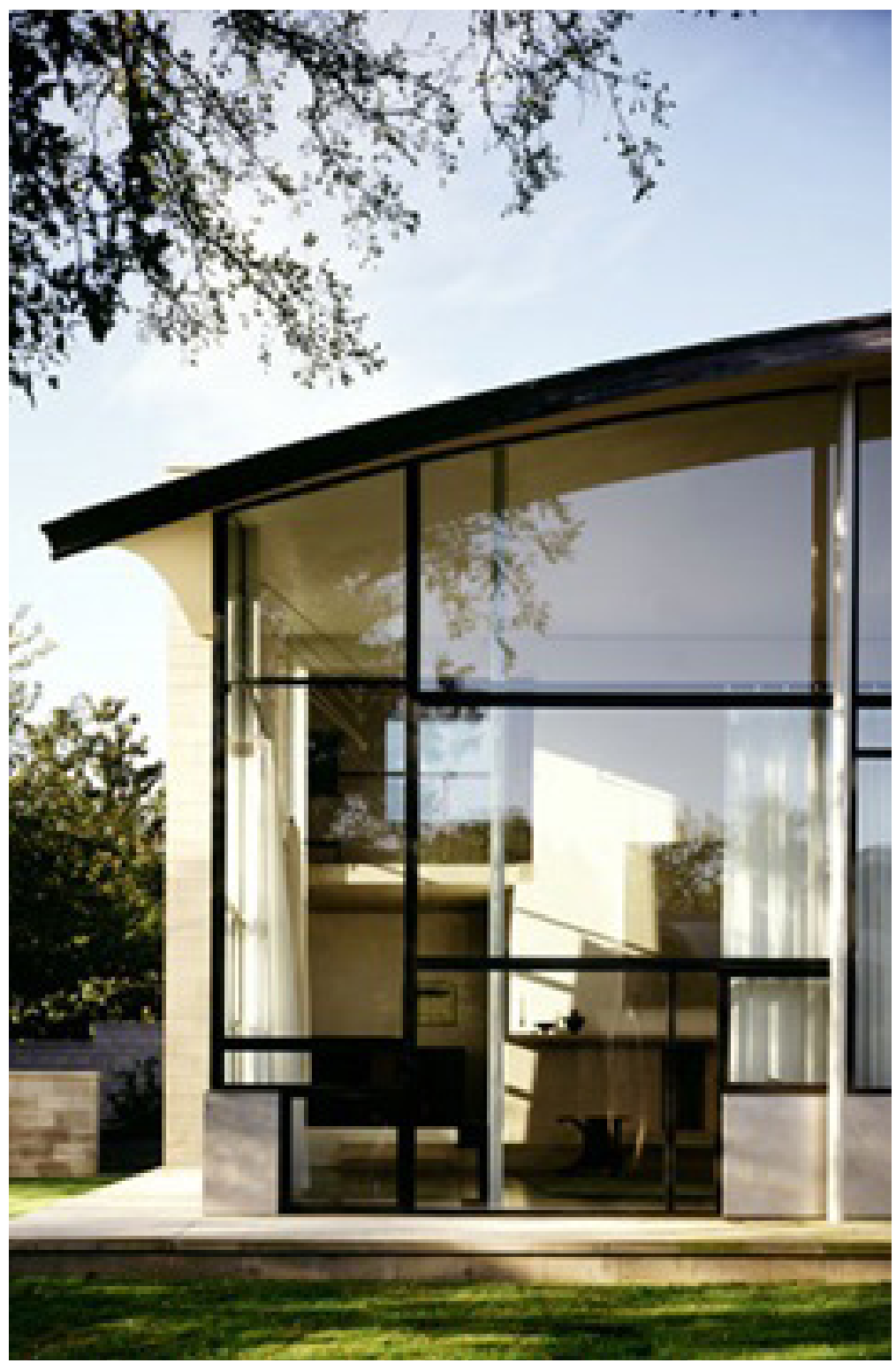

De Holl, S., (2015, www.stevenholl.com). 
Es necesario reconocer a Holl ya que entiende el potencial de la fenomenología de la luz en la creación de espacio arquitectónico. La obra de Holl revela una cuidadosa consideración de la materialidad, la luz, el color y la textura. Se debe notar, sin embargo, que, si el aspecto emocional de la arquitectura es fundamental en su trabajo, esto no es un fin en sí mismo, sino un medio para involucrar a la imaginación del habitante.

La manipulación de materiales y fenómenos son importantes para configurar un espacio arquitectónico que sea sensible, perceptible y emocionante, para la creación atmósferas dentro de la arquitectura. El término atmósfera fue designado para un libro por parte del arquitecto suizo Peter Zumthor, ganador del premio Pritzker en 2009 y uno de los arquitectos más importantes e influyentes de la actualidad. Zumthor plantea que la atmósfera habla de una sensibilidad emocional, una percepción que funciona a una velocidad y que parte precisamente de lo que se ve y se siente al momento de entrar a un recinto (Zumthor, 2006).

De la misma manera que sucede con Holl, se debe recurrir al ámbito filosófico, social y fenomenológico para descomponer la generación de espacios a través de ciertos elementos que sirvan para fines más prácticos y tangibles. Steven Holl expresa su interés por moldear el espacio y hacer partícipe al hombre en la generación de las sensaciones y emociones. Para ello define, en su obra Paralax (2000), el concepto de espacio:

The space is the essential medium of architecture. Space is simultaneously many things - the voids in architecture, the space around architecture, the vast space of landscape and city space, intergalactic spaces of the universe. Space is something both intrinsic and relational (p. 22).
Con la finalidad de concretizar las partes que crean, forman y manipulan el espacio, Holl ha desarrollado una serie de conceptos que manifiestan la posibilidad de cualificar el espacio, entre los que destacan los siguientes:

- Enmeshed experience

(Experiencia enredada)

- Chemistry of matter (Química de la materia)

- Speed of shadow

- Duration (Velocidad de la sombra) (Duración)

- Chromatic space (Espacio cromático)

- Hinged space

- Porosity (Espacio con bisagras) (Porosidad)

Para el análisis del espacio a través de configuradores, parto de la teoría de Steven Holl, pues propone un entrelazamiento (intertwining) que conlleva a una tricotomía entre la idea, el espacio y el material para lograr la generación del espíritu de la arquitectura.

Tomando como base el diagrama de Intertwining de Holl, se considera a la idea y al material como elementos imprescindibles en el entrelazamiento del espacio. En este ejemplo que propone, la metafísica de la luz nace del entrelazamiento de esencias con materiales cotidianos, formas y espacios. Esta metafísica se produce cuando se logra anclar todos los elementos necesarios en un sitio, tal como el autor lo ha llevado a cabo en varios de sus proyectos. 
Figura 9. Diagrama "Intertwining" de Steven Holl

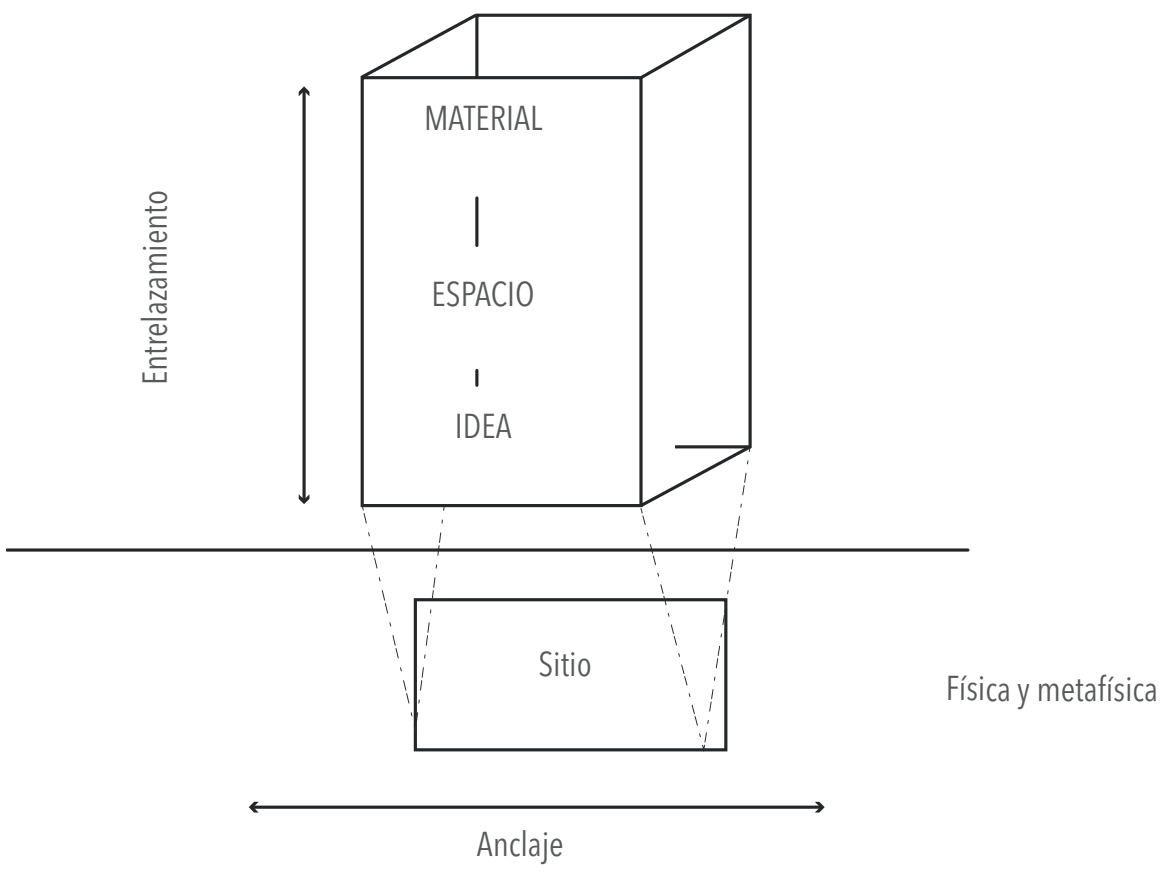

Paralelamente, Holl trabaja el diagrama anterior con otro elemento llamado "Criss-crossing" (cruzamiento), a través del cual manifiesta varias cualidades necesarias para la armonización y el protagonismo del espacio, mismas que al cruzarlas evocan el sentido tangible de la idea, el espacio y el material como elementos importantes que se articulan y perciben a través de la experiencia del ser en arquitectura.

\section{Discusiones}

Retomando lo establecido en este artículo, basado en arquitectos que se han dedicado a estudiar el concepto de espacio, se desprende que ha sufrido una evolución para poder entenderlo; desde Platón y Aristóteles con una filosofía de lo que existe y lo que no existe, pasando por el medioevo donde la presencia de Dios en el pensamiento de la época marca una tendencia para asimilar que el concepto de espacio existe, y con ello visualizar la complejidad que tiene la connotación incluso al llevarlo a la propia propuesta arquitectónica, es decir, comprender la cosmovisión del espacio para poder aplicarlo.

Algunas características que definen al espacio, como lo plantea Ynzenga, es que puede verse como un objeto de percepción desde el punto de vista Psicológico, tiene dimensiones y es limitado si se ve desde la Geometría y mantiene una relación con la materia y el tiempo si se analiza desde la Física. Esta complejidad de la cual se aborda el espacio, traduce la infinidad de exploraciones artísticas y arquitectónicas y caminos que se pueden desarrollar en el planteamiento del proyecto, incluso cada perspectiva mantiene un dominio cognitivo que es una herramienta para el arquitecto. 
Figura 10. Propuesta de Proyecto Arquitectónico a través de las perspectivas del concepto de espacio

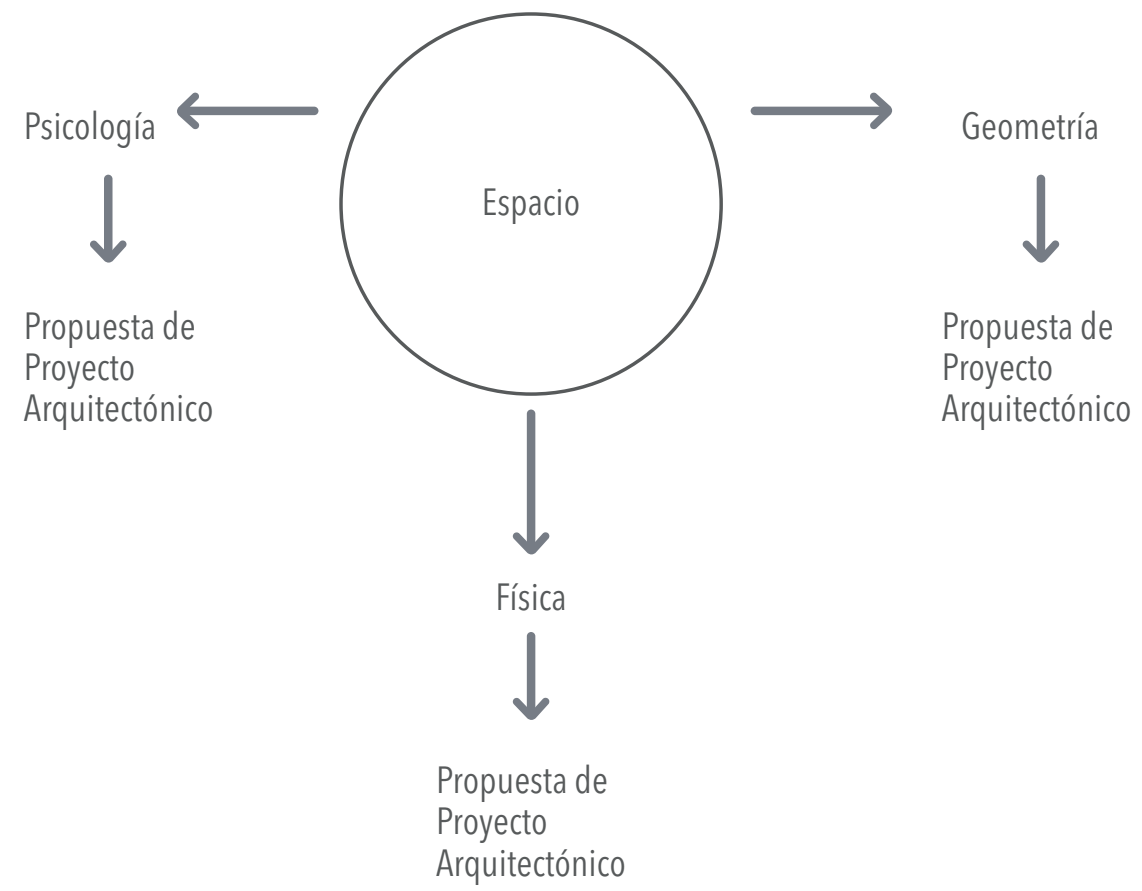

El espacio entonces es la parte medular de la arquitectura puesto que entenderlo, experimentarlo y vivirlo permite al ser comprender las articulaciones de fenómenos que hacen tocar el espíritu y la conciencia en el habitante. Los procesos que carecen de entender el espacio hacen visualizar una arquitectura sin alma, sin sentido, al no ser capaz de conmover ser del habitante y se vuelve una arquitectura sin protagonismo.

El espacio, cuando aceptamos que existe, es posible cualificarlo; para ello autores como Steven Holl, Alberto Pérez Gómez, Juhani Pallasmaa y Cristian Norberg Schulz, han estudiado la línea perceptual de este concepto. Resumiendo, algunos aportes, el espacio es necesario para la relación entre hombre y arquitectura, al mismo tiempo que entrelaza la idea con la materia. Estos enlaces son posibles gracias a fenómenos que nos permiten configurar el espacio con características fenomenológicas capaces de crear emociones en el habitante.

Las sensaciones emocionales, a través de la percepción pretenden funcionar a una velocidad impresionante que forman parte del día cotidiano del ser humano. Las cosas, la gente, el aire, los ruidos, los colores, las presencias materiales, las texturas y también las formas son parte del mundo fenoménico que nos hace disfrutar de la arquitectura y vincularnos con el lugar- Retomando la idea planteada por Peter Zumthor, el cuerpo de la arquitectura (el mundo material), el sonido, la temperatura, el entorno, la seducción, la tensión, la intimidad y la luz forman parte de las atmósferas que nos brinda el espacio, es decir el lenguaje propio e intangible de la arquitectura que nos lleva a este mundo metafísico capaz de entender la espiritualidad de una arquitectura hecha por el ser humano y para el ser humano; 
en otras palabras los elementos como los materiales hacen dotan al arquitecto de herramientas para jugar con las emociones del habitantes y hacer que cada experiencia se convierta en una virtud para mover emociones y presentar al habitante un mundo de experiencias icónicas, simbólicas y semióticas a través de un espacio arquitectónico que vuelve icónica a la arquitectura.

Finalmente, Steven Holl, como uno de los arquitectos que entrelaza a los fenómenos para experimentar la arquitectura, manifiesta esta dialogía entre el material y la experiencia para entender la idea del arquitecto. El uso de fenómenos en el diseño arquitectónico, presenta una manera de explorar el espacio arquitectónico y las herramientas son variables: el uso de la luz, la oscuridad, el vértigo, el material, lo traslúcido, lo colgante, lo frío, lo poroso, lo rugoso, las aberturas delgadas, ubicaciones, equilibrio, formas y direcciones, movimiento, ritmo, organización, conectividades, asociaciones, ambigüedades, virtualidades, contrastes, entre otros.

Estas cualidades que adquiere la exploración del espacio arquitectónico, ayudan a tener una diversidad de emociones y experiencias que se entrelazan como lo recalca la articulación de Steven Holl, y son esencias con las que los arquitectos pueden explorar bajo la incertidumbre de que el resultado es tan diverso que mantiene la capacidad de asombro en los modelos y que posteriormente se llevan a la realidad.

Figura 11. Exploraciones perceptuales en el proyecto arquitectónico

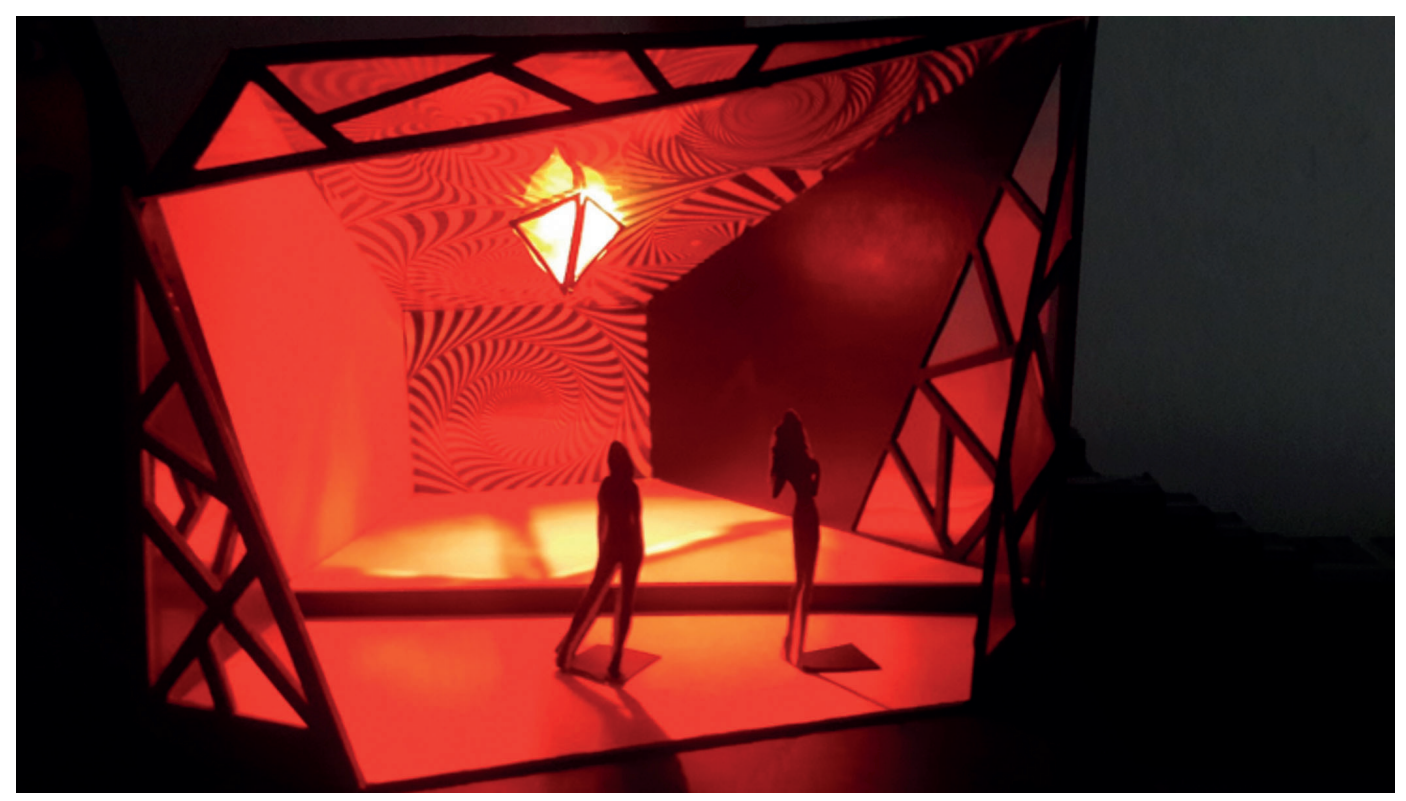

De Velázquez Acosta, (2013, estudiante de primer grado de la Carrera de Arquitectura). 


\section{Referencias}

Alvarez-Gayou Jurgenson, J. L. (2003). Cómo hacer investigación cualitativa -fundamentos y metodología-. Paidós Educador.

Aparicio Guisado, J. M. (2008). Construir con la razón y los sentidos (1era ed.). Nobuko.

Artemis. (1993). Steven Holl. Artemis.

Breuer, M. (1955). Sun And Shadow "the philosophy on Architect". Dodd, mead \& company.

Casado Martínez, R. (2005). La Sombra y la Forma del Espacio Arquitectónica; Realidad y ficcion del espacio arquitectonico. el proyecto y la sombra. Escuela Técnica Superior de Arquitectura; Universidad de Sevilla, Departamento de proyectos.

Dreher, J. (2012). Fenomenología: Alfred Schütz y Thomas Luckman. En E. De la Garza Toledo, \& G. Lyeva, Tratado de metodología de las ciencias sociales: Perspectivas Actuales (pp. 96-133). Fondo de la Cultura Económica.

Frampton, K. (2003). Steven Holl Architect Kenneth Framtom. Electaarchitecture.

H. Forgus, R., \& E. Melamed, L. (2010). Percepción: estudio del desarrollo cognoscitivo. Trillas.

Holahan, C. J. (2011). Psicología Ambiental: Un enfoque general. Limusa.

Holl, S. (1996). Intertwinig: selected projects 1989 - 1995 (1 era ed.). Princeton Architectural Press.

Holl, S. (2011). Cuestiones de Percepción. Fenomenología de la arquitectura. Gustavo Gili.

Kahn, L. (1957). El Orden de los espacios y la Arquitectura.

Montaner, J. M. (2007). Arquitectura y Crítica (2da ed.). Gustavo Gili.

Moran, D. (2011). Introducción a la Fenomenología. Anthropos.

Muñoz Cosme, A. (2008). El Proyecto de Arquitectura. Reverté.

Norberg - Schulz, C. (2008). Intenciones en Arquitectura (primer edición ed.). Gustavo Gili.

Ortega y Gasset, J. (1982). Meditación de la técnica y otros ensayos sobre ciencia y filosofía. Revista de Occidente (21).

Pallasma, J. (2006). Los ojos de la piel: la arquitectura y los sentidos (primera edición ed.). Gustavo Gilli.

Pedragosa Bofarull, P. (8 de abril de 2014). La fenomenología en la investigación. (J. Sánchez García, entrevistador).

Plummer, H. (2009). La arquitectura de la luz natural. Blume.

Reza Shirazi, M. (2014). Towards an articulated phenomenalogical interpretation of architecture -phenomenal phenomenology-. Routledge.

Sartre, J. P. (2012). Bosquejo de una teoría de las emociones. Alianza.

Ynzenga Acha, B. (2013). La materia del espacio arquitectónico. Nobuko.

Zevi, B. (1981). Saber ver la arquitectura. Poseidon.

Zumthor, P. (2006). Atmósferas. Gustavo Gili. 